\title{
Microstructural Changes and Mechanical Response of Aluminum-Based Composites Prepared with Dispersed $\mathrm{CeO}_{2}$ Nanoparticles
}

\author{
Francisco J. Baldenebro-López $(\mathbb{D}),{ }^{1}$ Raúl Peréz-Bustamante $(\mathbb{D}),{ }^{2}$ Ivanovich Estrada-Guel $(\mathbb{D}),{ }^{3}$ \\ Roberto Martínez-Sánchez, ${ }^{3}$ Alberto Duarte-Moller ${ }_{(D)}{ }^{3,4}$ and \\ Cynthia D. Gómez-Esparza (i) $^{3}$
}

${ }^{1}$ Facultad de Ingeniería Mochis, Universidad Autónoma de Sinaloa, Los Mochis 81223, Mexico

${ }^{2}$ CONACYT-Corporación Mexicana de Investigación en Materiales S.A. de C.V., Saltillo 25290, Mexico

${ }^{3}$ Centro de Investigación en Materiales Avanzados Materiales S.C., Chihuahua 31136, Mexico

${ }^{4}$ Universidad de LaSalle Bajío, Av. Universidad 602, León, Gto. 37150, Mexico

Correspondence should be addressed to Alberto Duarte-Moller; jduarte@delasalle.edu.mx and

Cynthia D. Gómez-Esparza; cynthia.gomez@cimav.edu.mx

Received 26 November 2018; Accepted 27 December 2018; Published 2 July 2019

Academic Editor: Antonio Riveiro

Copyright @ 2019 Francisco J. Baldenebro-López et al. This is an open access article distributed under the Creative Commons Attribution License, which permits unrestricted use, distribution, and reproduction in any medium, provided the original work is properly cited.

The effect of $\mathrm{CeO}_{2}$ nanoparticles on the microstructure of two different metal matrixes, AA2024 aluminum alloy and pure aluminum, were studied. The aluminum-based composites were synthesized by mechanical milling and subsequently sintering at $550^{\circ} \mathrm{C}$ under an argon atmosphere. The microstructural evolution of consolidated composites was evaluated by scanning electron microscopy, transmission electron microscopy, and $\mathrm{X}$-ray diffraction. The experimental results revealed that the addition of $\mathrm{CeO}_{2}$ nanoparticles in the AA2024 alloy produced a dispersed needle-like $\mathrm{Ce}$-Cu-rich phase that reduces the hardness of samples after sintering. On the contrary, the dispersion of $\mathrm{CeO}_{2}$ in pure aluminum shows significant improvement of hardness in comparison with the reinforced and unreinforced AA2024 aluminum alloy. During the sintering, the $\mathrm{CeO}_{2}$ nanoparticles show higher chemical stability in the aluminum matrix in comparison with the AA2024 matrix.

\section{Introduction}

Aluminum and its alloys are attractive alternatives to replace some ferrous materials in many industrial applications because of their intrinsic properties, such as good machinability, surface finish capabilities, damage tolerance, low density, high specific strength, and good thermal and electrical conductivity [1-6]; all the above is combined with good mechanical properties. Aluminum alloys are excellent candidates for the synthesis of metal matrix composites (MMCs). Here, the addition of nanoparticles for the synthesis of MMCs combines the high ductility and low density of the metallic matrix with the beneficial hardness and stiffness of reinforcement particles, resulting in the generation of advanced materials with an excellent mechanical response [7].
For aluminum reinforcement, several metal oxide particles are excellent options to take into account. Moreover, the addition of oxides at the nanometric scale can improve the mechanical properties of the MMCs by reducing the interparticle spacing. Unfortunately, fine particles present a higher tendency toward heavy agglomeration. The strengthening mechanisms, i.e., nanoparticles addition, have a strong relationship based on their type, size, morphology, volume fraction, and distribution, as well during the composite synthesis.

From the wide variety of synthesis routes to prepare MMCs, the solid routes based on powder metallurgy (PM) provide better results regarding their versatility and ability to produce homogeneous dispersions of secondary phases into the aluminum matrixes. The PM process involves the mixing 
of reinforcement particles with the metal matrix (in powder form), followed by cold consolidation and sintering steps. The mechanical response of aluminum and its alloys can be enhanced with the use of mechanical alloying (MA) and/or mechanical milling (MM) techniques.

There is an increased interest for the development of advanced materials using some aircraft grade aluminum alloys as the metal matrix of composites preparation. The AA2024 aluminum alloy is extensively used in the aerospace industry due to their high strength, excellent wear resistance, lightweight, and good casting characteristics [6]. At present, some research is conducted looking for improving the physical characteristics, mechanical properties [8], and corrosion resistance [9-11] of aluminum alloys by Ce addition. Due to the above, the AA2024 alloy constitutes an excellent candidate as a metal matrix to be reinforced with $\mathrm{CeO}_{2}$ nanoparticles.

In the present study, two metallic matrixes were selected: pure aluminum and a commercial AA2024 aluminum alloy. The aim of the present work is to study the effect of $\mathrm{CeO}_{2}$ nanoparticles dispersion on the microstructure of pure aluminum and AA2024 aluminum alloy, investigate the stability of these nanoparticles, and observe their interaction with the alloying elements.

\section{Materials and Methods}

The $\mathrm{CeO}_{2}$ nanoparticles were dispersed in two different aluminum-based materials by the mechanical milling route. Pure Al powder and AA2024 burrs (Table 1) were used as metal matrixes. The commercial $\mathrm{CeO}_{2}$ nanoparticles and $\mathrm{Al}$ powder (purity 99.5\%) were supplied from Alfa Aesar company. For composite preparation, $\mathrm{CeO}_{2}$ nanoparticles were used in a concentration of $5 \mathrm{wt}$. percent. The weighted mixtures were processed in a hardened steel vial filled with 3 balls of $13 \mathrm{~mm}$ and 3 balls of $11 \mathrm{~mm}$ (in diameter) with a ball-to-powder ratio of 5:1 (in wt.), and the vial was sealed under an argon atmosphere. The MM process was performed at room temperature in a high-energy ball mill SPEX $8000 \mathrm{M}$. The milling time was set to $3 \mathrm{~h}$. Methanol was used as a process control agent (to avoid agglomeration of the highly ductile Al particles). Some consolidated composites were fabricated by uniaxial cold pressing at $900 \mathrm{MPa}$ during $60 \mathrm{~s}$. The compacted samples in the cylindrical form of $5 \mathrm{~mm}$ in diameter were then sintered for different times ( 1 to $7.5 \mathrm{~h}$ ) at $550^{\circ} \mathrm{C}$ under an argon atmosphere with a heating rate of $50^{\circ} \mathrm{C} / \mathrm{min}$. The characterization was done through scanning electron microscopy (SEM) in a JEOL JSM7401F and a Hitachi SU3500 microscope, both coupled with an energy dispersive spectrometer, and the transmission electron microscopy (TEM) was carried out with a JEOL-JEM2200FS device. The microhardness testing was performed on the consolidated composite samples using a Leco Microhardness tester LM 300AT under $200 \mathrm{~g}$ load and $10 \mathrm{~s}$ of dwell time.

\section{Results and Discussion}

3.1. Powder Characterization. Figure 1(a) shows a representative TEM image from the as-received $\mathrm{CeO}_{2}$ particles. The size of the $\mathrm{CeO}_{2}$ nanoparticles is in the range of 10$50 \mathrm{~nm}$. The elemental EDS analysis performed on the
TABLE 1: Composition of the AA2024 alloy (wt.\%).

\begin{tabular}{lccccc}
\hline $\mathrm{Al}$ & $\mathrm{Cu}$ & $\mathrm{Mg}$ & $\mathrm{Mn}$ & $\mathrm{Si}$ & $\mathrm{Fe}$ \\
\hline Balance & 4.5 & 1.5 & 0.6 & 0.5 & 0.4 \\
\hline
\end{tabular}

nanoparticles confirms the composition of the cerium oxide, and the $\mathrm{C}$ content came from the carbon film that supports the sample. Figure 1(b) shows the XRD patterns from the $\mathrm{CeO}_{2}$ nanoparticles. The nanoceria presents a single-phase with a fluorite-type crystallographic structure. All peaks were indexed as $\mathrm{CeO}_{2}$ (ICDD 034-0390 card) with a lattice constant of $5.411 \AA$ and Fm-3 m space group.

Some dark-field TEM micrographs of the AA2024- $\mathrm{CeO}_{2}$ and the $\mathrm{Al}-\mathrm{CeO}_{2}$ are presented in Figure 2. Figure 2(a) shows two dark-field TEM images of the AA2024- $\mathrm{CeO}_{2}$ powder composite after $3 \mathrm{~h}$ of milling. Many bright rounded-like phases uniformly dispersed into the aluminum matrix are observed. The EDS-TEM analyses and elemental mapping show that rounded bright phases have a high $\mathrm{Ce}$ and $\mathrm{Cu}$ concentration in comparison with the aluminum matrix. Pandey et al. [12] reported in their work the grain refiner effect of the nanoceria addition in a $\mathrm{Cu}-\mathrm{Al}-\mathrm{Ni}$ shape memory alloy. The authors observed a nearly uniform distribution of $\mathrm{CeO}_{2}$ on the $\mathrm{Cu}$-based alloy; furthermore, $\mathrm{Cu}$ favours the dissolution of $\mathrm{CeO}_{2}$. Based on this evidence, it is suggested that $\mathrm{Al}$ and $\mathrm{Cu}$ of the AA2024 alloy could reduce the $\mathrm{CeO}_{2}$, forming a $\mathrm{Cu}-\mathrm{Ce}$ phase. On the other hand, Figure 2(b) shows that Ce-rich phases found in the pure aluminum matrix present a faceted morphology, noticeably different to the first observed (Cu-Ce phases).

\subsection{Microstructural Characterization of Bulk Composites.} Figure 3 shows some SEM micrographs exhibiting the microstructural evolution of AA2024- $\mathrm{CeO}_{2}$ composites at different sintering times ( 1 to $7.5 \mathrm{~h}$ ). A bright phase is present in the microstructure of all samples; however, the volume fraction and size of these bright phase increase and its morphology changes from irregular to a needle-like shape after $2 \mathrm{~h}$ of sintering. A noticeable variation on the porosity as a direct function of the sintering time was also observed.

The chemical composition of the bright phase observed in Figure 3 was analyzed by SEM elemental mapping (Figure 4). The formation of needle-shaped $\mathrm{Ce}-\mathrm{Cu}$-rich phases in the bulk AA2024- $\mathrm{CeO}_{2}$ composites was confirmed. Tian-Jiao et al. [13] investigated the influence of $\mathrm{CeO}_{2}$ addition on the microstructure and tensile properties of the AA2024 alloy, reporting that cerium (IV) oxide can be reduced partly to metallic cerium by aluminum, and new phases such as $\mathrm{Al}_{3} \mathrm{Ce}$ and $\mathrm{CeCu}_{2}$ are formed during cerium interactions with aluminum and copper. After a relative short sintering time, the affinity of $\mathrm{Cu}$ with $\mathrm{Ce}$, which was enhanced during the milling process, remains after sintering (Figure 2(a)). According to the elemental mapping, the needles contain an important concentration of $\mathrm{Ce}, \mathrm{Cu}$, and $\mathrm{Si}$. In addition, a graph with the hardness of $\mathrm{AA} 2024-\mathrm{CeO}_{2}$ composites is presented in Figure 4. A tendency for reduction of hardness as a function of sintering time is observed. The well-known solid 


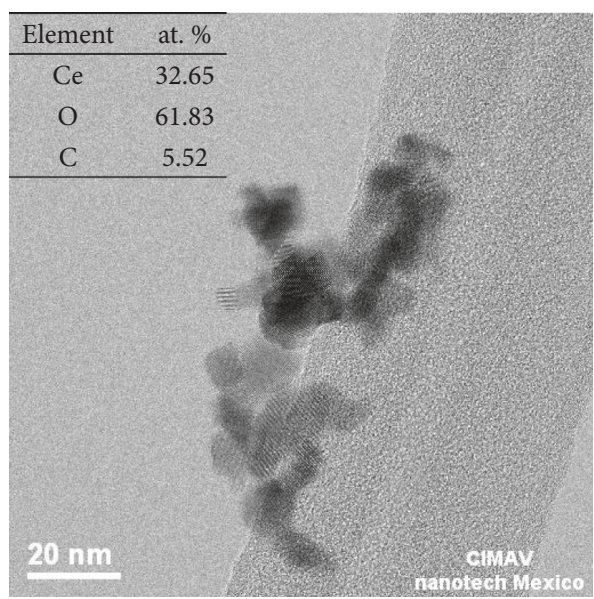

(a)

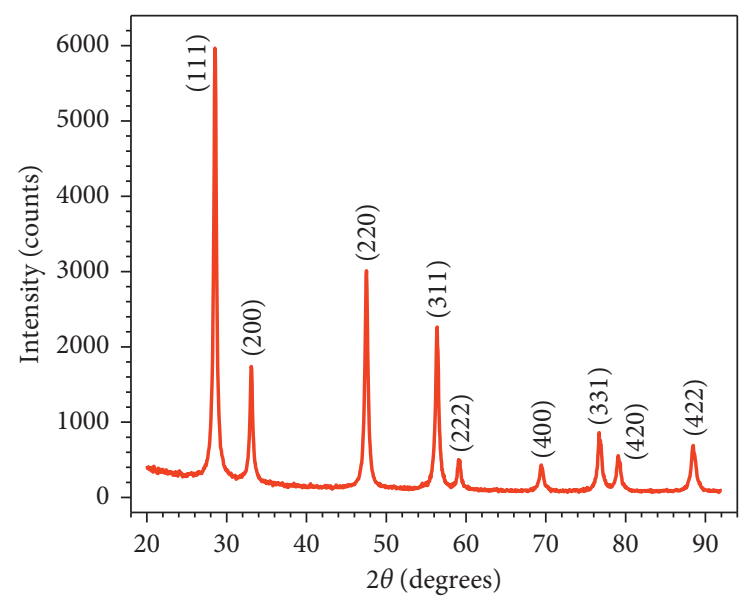

(b)

FIgURE 1: (a) TEM micrograph and (b) XRD pattern of $\mathrm{CeO}_{2}$ nanoparticles.

solution strengthening mechanism provided by $\mathrm{Cu}$ and $\mathrm{Si}$ in the AA2024 alloy is reduced because of their affinity with Ce inducing a negative effect on the mechanical response of composites as will be explained below.

Copper plays an important role in strengthening aluminum aircraft alloys such as AA2024-T6 due to the precipitation strengthening phenomena occurred during solution and artificial aging. The amount, distribution, and size of the precipitated phase play an important role in the strengthening rate, depending largely on the composition and processing route of the alloys [14], affecting the mechanical properties of the alloy. Hence, it is expected a negative effect on the mechanical performance of the AA2024 alloy due to the chemical affinity between $\mathrm{Cu}$ and $\mathrm{Ce}$, which form phases that alter the kinetics of precipitation of AlCuX solutes. In addition, the morphology of the phases creates a high density of stress concentrator zones with undesirable effects on ductility and hardness.

The images from Figure 5 show the microstructure of Al$\mathrm{CeO}_{2}$ composite after sintering at $550^{\circ} \mathrm{C}$ during $3 \mathrm{~h}$. In the SEM image of Figure 5(a), a homogeneously dispersed bright phase with irregular and rounded morphology in the form of agglomerates, lesser than $5 \mu \mathrm{m}$ in size, is observed. The EDS analyses corroborate the composition as a Ce-rich phase (yellow square in Figure 5(a)). In comparison with the AA2024- $\mathrm{CeO}_{2}$ composite, the needle-like phase is not observed, even after $3 \mathrm{~h}$ of sintering. Perez-Bustamante et al. [15] reported the effect of Al-6Ce-3La (ACL) master alloy additions on the AA7075 powder alloy. They found the presence of large needle-like Ce-La phases in the ACL master alloy. The use of mechanical milling to incorporate the ACL master alloy into A7075 had a positive effect on the reduction of needle-like morphology; however, the microstructural evolution at sintering temperatures was not evaluated.

Some TEM observations were carried out on the abovementioned agglomerated bright phase. The TEM micrograph displayed in Figure 5(b) gives evidence about the formation of nanoscaled faceted Ce-rich nanophases. Figure 5(c) presents a detailed view of the yellow square shown in Figure 5(b). It is observed a faceted morphology of bright nanophases found in $\mathrm{Al}-\mathrm{CeO}_{2}$ nanocomposites and the formation of an interface located between the cerium oxide nanoparticle and the aluminum matrix. Figure 5(d) displays a high-resolution micrograph (HRTEM) where the interface between a $\mathrm{CeO}_{2}$ nanoparticle and the metallic aluminum matrix is appreciable. We can notice four main zones indicating their interplanar distances (Figure 5(e)); zones 1 and 4 show a crystalline structure corresponding to the pure aluminum and $\mathrm{CeO}_{2}$ nanoparticle, respectively. The interplanar distance of $0.202 \mathrm{~nm}$ for the pure $\mathrm{Al}$ corresponds to the plane (200) and that of $0.192 \mathrm{~nm}$ for the $\mathrm{CeO}_{2}$ corresponds to the plane (311). The zone 2 corresponds to the interface between $\mathrm{CeO}_{2} / \mathrm{Al}$, where the calculated interplanar distance $(2.58 \mathrm{~nm})$ is different from that corresponding to the pure aluminum. In Figure 5(f) is displayed the selected area electron diffraction (SAED) pattern and the corresponding simulated diffraction pattern of the same place (interface) based on the $\mathrm{Al}_{2} \mathrm{O}_{3}$ crystalline structure. The experimental and simulated patterns agree well with each other. A small variation in the interplanar distance of the zone between $\mathrm{CeO}_{2}$ nanoparticle and interface was detected and labeled as zone 3. According to the crystallography information of the ICSD card number 00-078-0484, the interplanar distance of $0.194 \mathrm{~nm}$ corresponds to the plane of the $\mathrm{Ce}_{2} \mathrm{O}_{3}$. A partial reduction of $\mathrm{CeO}_{2}$ to $\mathrm{Ce}_{2} \mathrm{O}_{3}$ led to the formation of the $\mathrm{Al}_{2} \mathrm{O}_{3}$ interface.

In order to evaluate the chemical stability of the added nanoparticles and their reinforcement capacity, the sintered samples (AA2024- $\mathrm{CeO}_{2}$ and $\mathrm{Al}-\mathrm{CeO}_{2}$ ) were added to a pure AA2024 melted alloy at $750^{\circ} \mathrm{C}$ using a concentration of $1 \%$ (in wt.). Figure 6 displays some SEM micrographs showing the microstructure of the pure AA2024 alloy in as-cast condition (Figure 6(a)), AA2024 alloy + AA2024- $\mathrm{CeO}_{2}$ composite (Figure 6(b)) and AA2024 with $\mathrm{Al}-\mathrm{CeO}_{2}$ composite (Figure 6(c)). A dendritic microstructure for the pure AA2024 alloy is observed, as is expected for an alloy produced following a liquid route (casting). The addition of the AA2024- $-\mathrm{CeO}_{2}$ composite led to the formation of coarse precipitates with needle-like microstructure, while the 

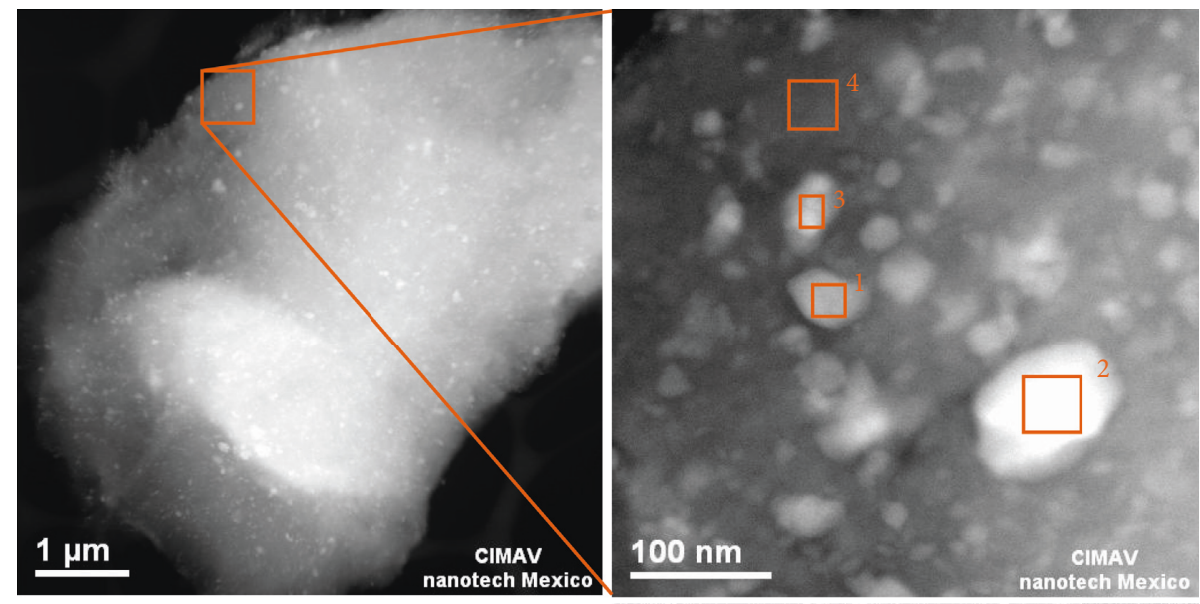

\begin{tabular}{l|ccccc}
\hline Spectrum & $\mathrm{C}$ & $\mathrm{O}$ & $\mathrm{Al}$ & $\mathrm{Cu}$ & $\mathrm{Ce}$ \\
\hline 1 & 2.44 & 1.20 & 92.34 & 2.07 & 1.95 \\
2 & 2.14 & 4.47 & 82.35 & 6.21 & 4.83 \\
3 & 1.81 & 1.18 & 90.49 & 3.62 & 2.90 \\
4 & 2.06 & 0.46 & 96.31 & 0.81 & 0.36
\end{tabular}

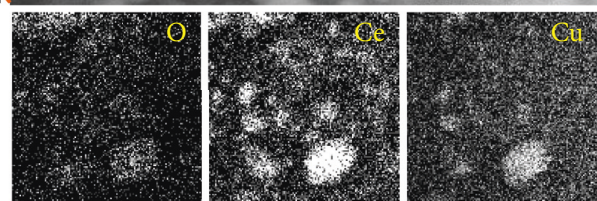

(a)
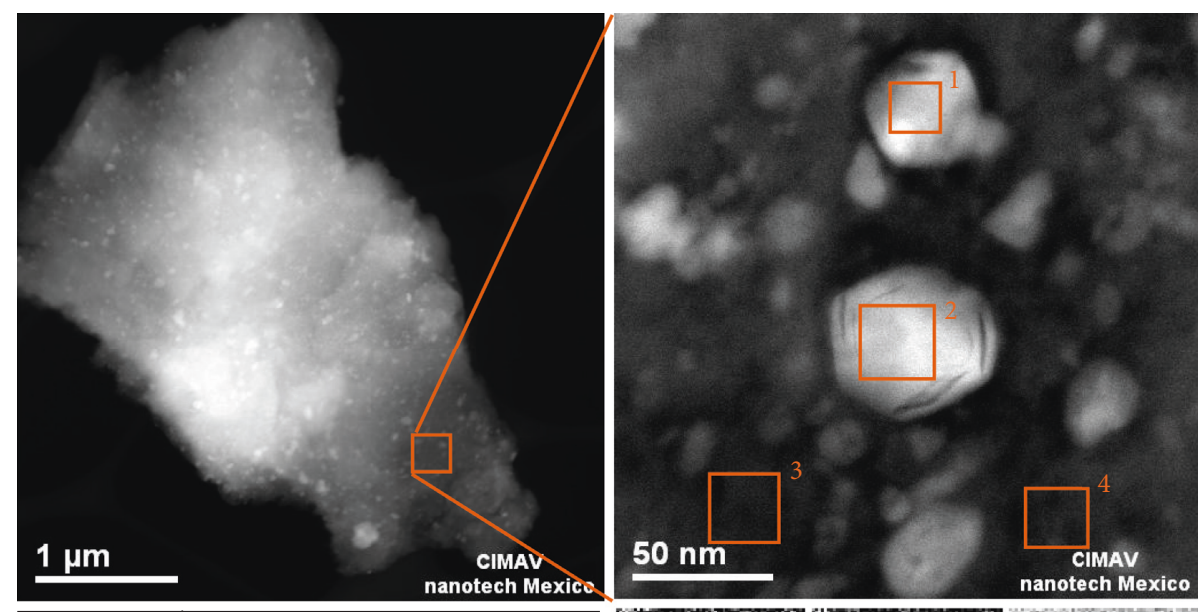

\begin{tabular}{l|cccc}
\hline Spectrum & $\mathrm{C}$ & $\mathrm{O}$ & $\mathrm{Al}$ & $\mathrm{Ce}$ \\
\hline 1 & & 12.05 & 83.26 & 4.69 \\
2 & & 12.72 & 82.67 & 4.60 \\
3 & 1.12 & 3.14 & 95.74 & \\
4 & 1.97 & 4.26 & 93.77 &
\end{tabular}

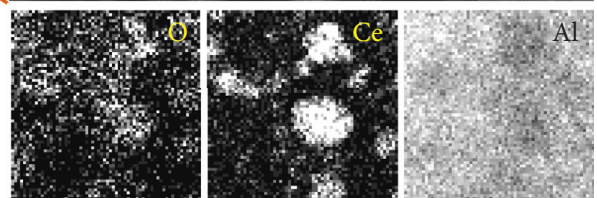

(b)

FIgure 2: TEM-DF micrograph, EDS analyses (in wt.\%), and elemental mapping of (a) $\mathrm{AA}_{2} 24-\mathrm{CeO}_{2}$ and (b) $\mathrm{Al}_{-}-\mathrm{CeO} \mathrm{O}_{2}$ powder samples after MM.

$\mathrm{Al}-\mathrm{CeO}_{2}$ composite acts as a grain refiner agent inducing the formation of a refined dendritic microstructure. There is no evidence of unwanted chemical reactions between the added ceria and the aluminum matrix, even though the process was carried out at a higher temperature where the chemical reactions between components are increased by the heat effect. In a liquid process, in which the cooling rate is slow, the dispersed material in the metal has enough time to grow, resulting in the formation of a coarse microstructure, detrimental to the mechanical response. In order to act as a reinforcement in the metal matrix and improve the mechanical response, the dispersed material would maintain a fine microstructure uniformly distributed in the matrix.
3.3. Mechanical Testing. Some microhardness results of sintered composites in the Vickers scale are displayed in Figure 7(a). For comparison purposes, the microhardness of a reference AA2024 alloy processed following the same sintering condition is presented. In both cases, the $\mathrm{Al}$ and the AA2024 showed an increase of hardness compared to the reference alloy. It has been reported that rare earth addition also improves several intrinsic properties of $\mathrm{Al}$ alloys such as strength, heat resistance, and corrosion resistance $[16,17]$. Even though the addition of 5.0 percent (in wt.) of $\mathrm{CeO}_{2}$ nanoparticles increases $\sim 5 \%$ the hardness of the unreinforced AA2024 alloy, a noticeable result is achieved with the $\mathrm{Al}-\mathrm{CeO}_{2}$ composite which presents an increase of $\sim 32 \%$ 


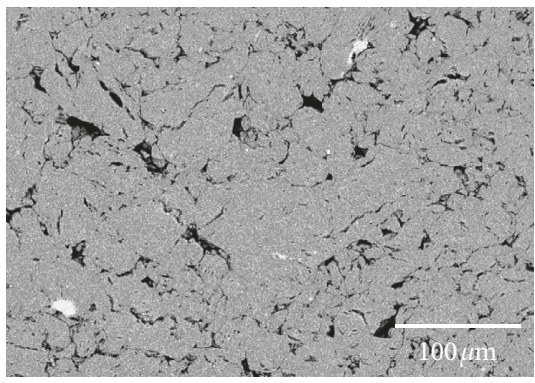

(a)

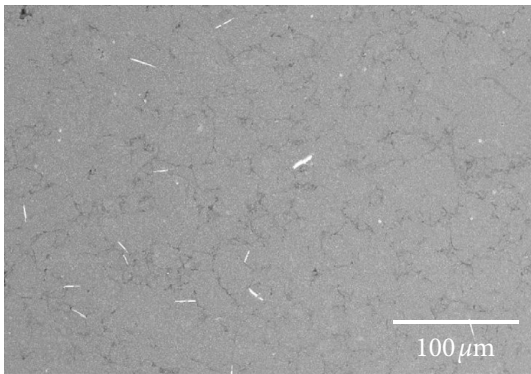

(d)

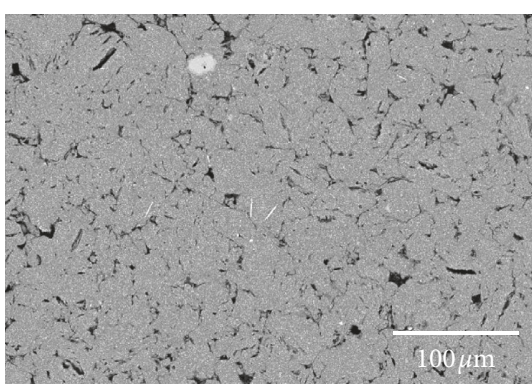

(b)

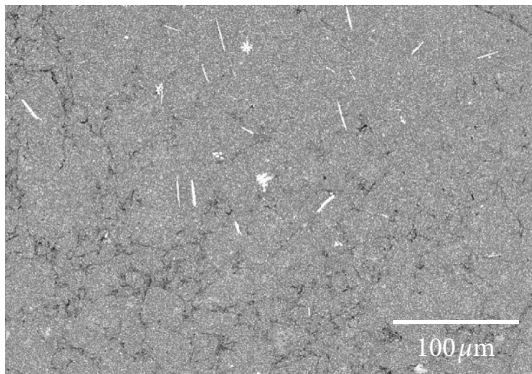

(e)

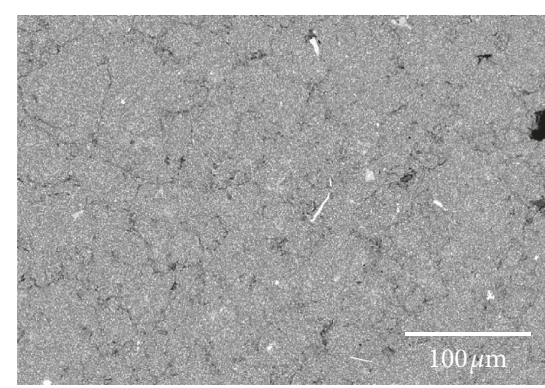

(c)

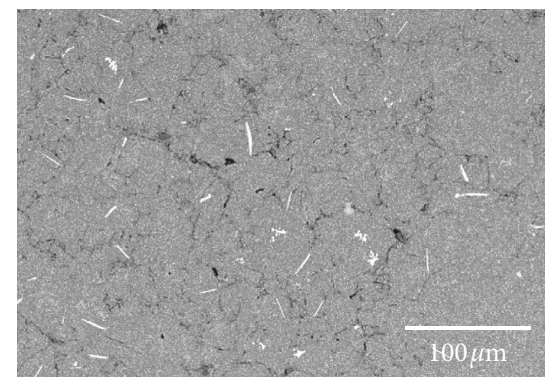

(f)

Figure 3: SEM images showing the microstructural changes of AA2024-CeO 2 composite after sintering. (a) 1 h. (b) $2 \mathrm{~h}$. (c) $3 \mathrm{~h}$. (d) $4 \mathrm{~h}$. (e) $5 \mathrm{~h}$. (f) $7.5 \mathrm{~h}$.

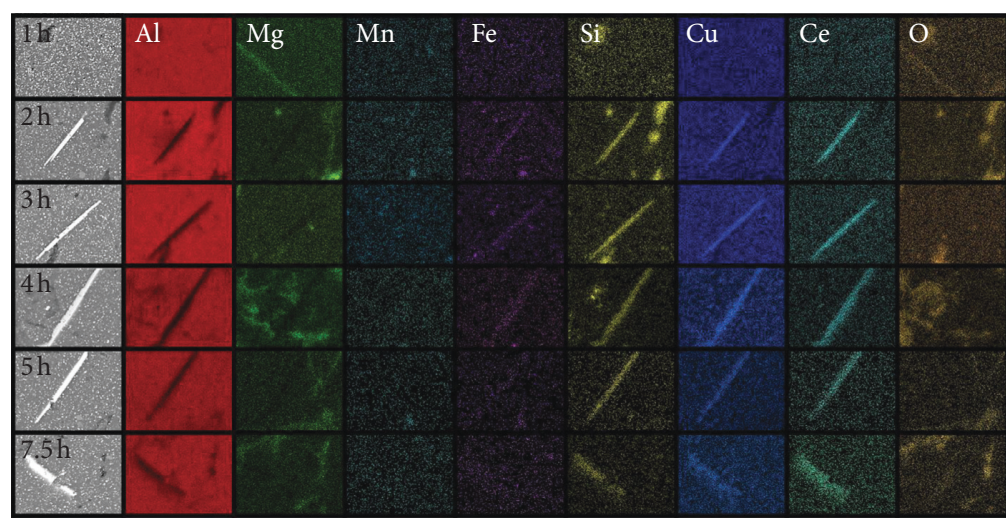

(a)

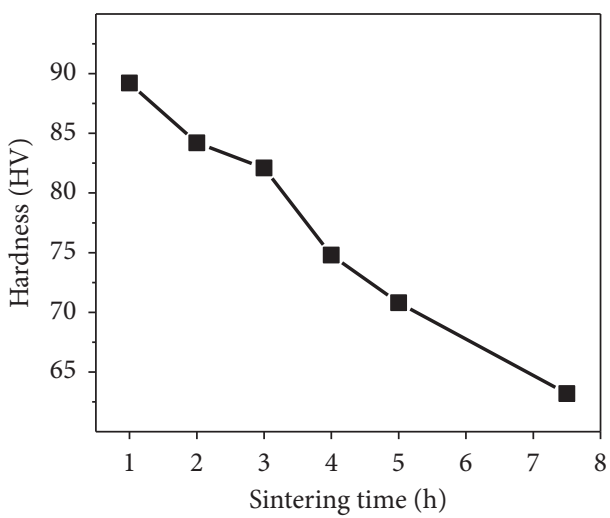

(b)

Figure 4: EDS mapping (a) and hardness (b) of the $\mathrm{AA} 2024-\mathrm{CeO}_{2}$ composite after sintering.

compared to the blank. It should be mentioned that the hardness of the $\mathrm{Al}-\mathrm{CeO}_{2}$ composite exceeds more than twice to that of the pure aluminum (49 HV).

In Figure 7(b) are presented the hardness of the casted AA2024 alloy with $1 \%$ additions of both prepared AA2024$\mathrm{CeO}_{2}$ and $\mathrm{Al}-\mathrm{CeO}_{2}$ composites; it is observed a remarkable difference between them: the AA2024- $\mathrm{CeO}_{2}$ composite increases $\sim 11 \%$ the hardness of the AA2024 alloy while the Al$\mathrm{CeO}_{2}$ composite improves its hardness over $50 \%$. The results indicate that additions of nanoceria have a positive effect on the mechanical properties of prepared composites; however, the presence of the alloying elements affects the response of the composites. It is observed that the addition of cerium oxide acts as a positive reinforcement for pure aluminum matrix, causing fall in mechanical behaviour of $\mathrm{Al}-\mathrm{Cu}$ alloys as a result of the chemical affinity between $\mathrm{Ce}$ and $\mathrm{Cu}$ (as was above mentioned) and the general morphology of the formed phases, affecting negatively the mechanical properties of the synthesized composites exposed in this study and considering for future studies, the effect produced by nanoparticles of this nature in the $\mathrm{Al}-\mathrm{Cu}$ alloys under corrosive and thermomechanical evaluation.

\section{Conclusions}

The present study showed the viability for production of two composites using as reinforcement material ceria nanoparticles and two different metal matrixes, pure aluminum and a commercial AA2024 alloy, used frequently in the aeronautical industry. Both composites were 


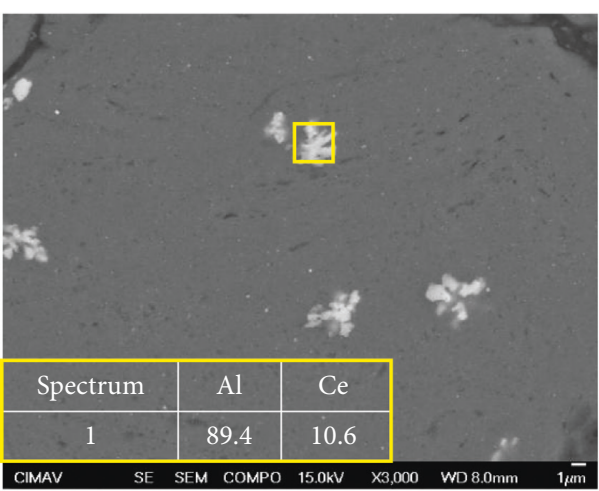

(a)

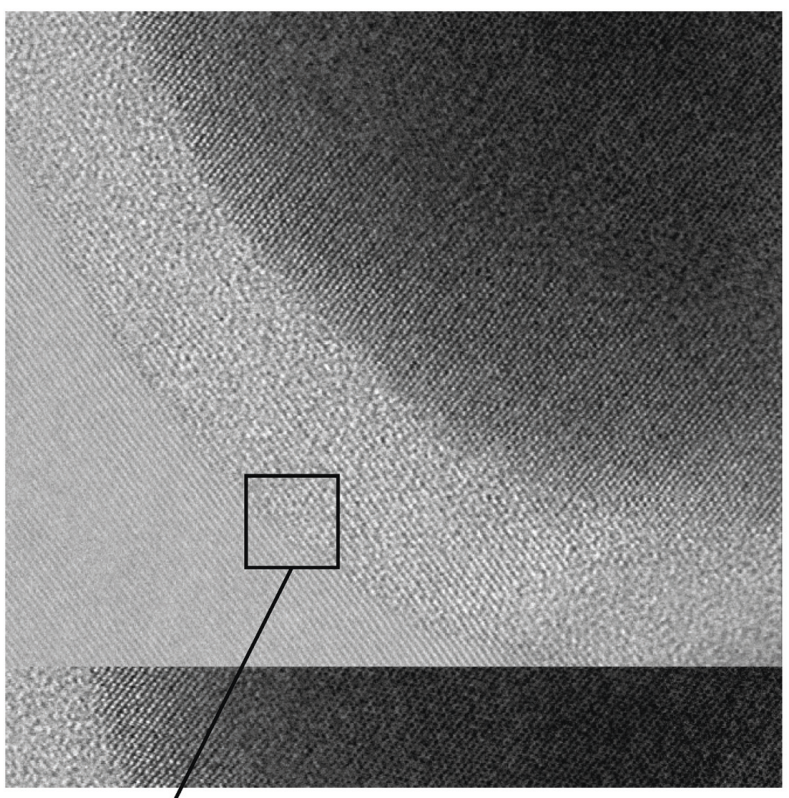

(d)

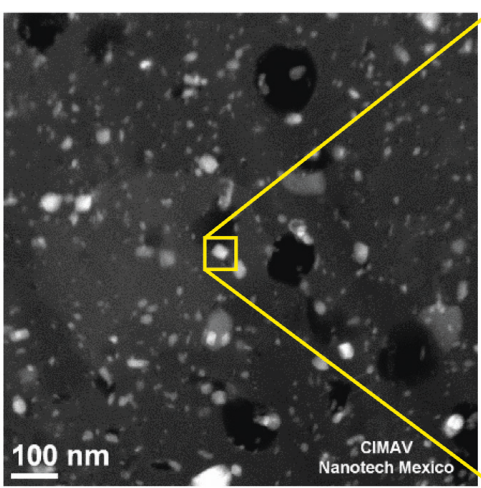

(b)

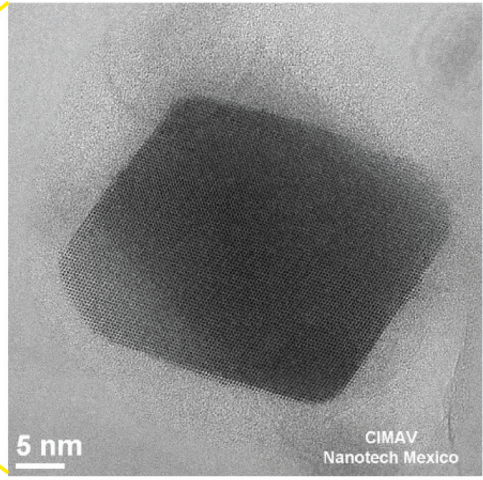

(c)

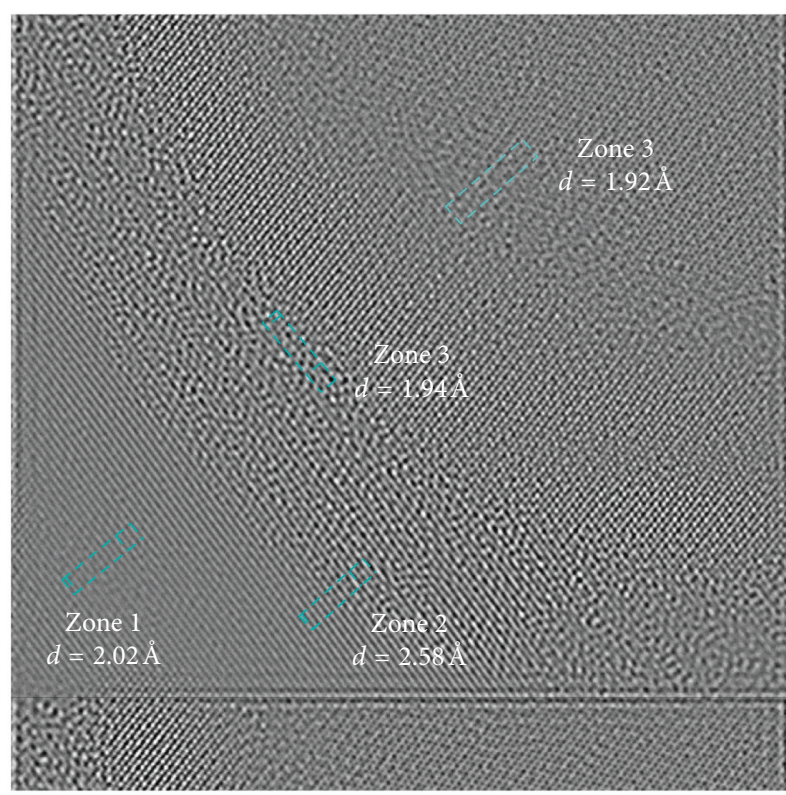

(e)

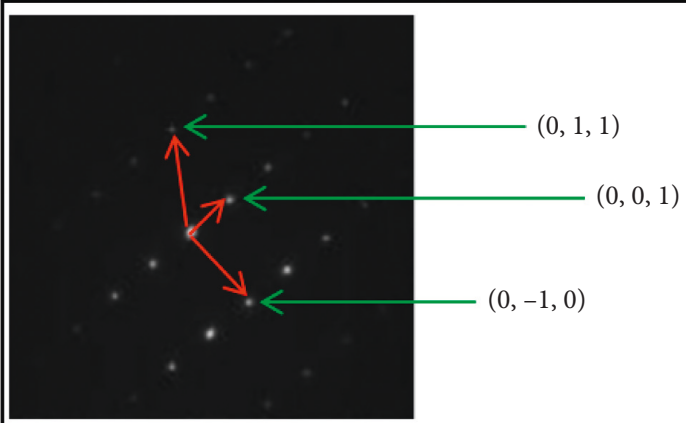

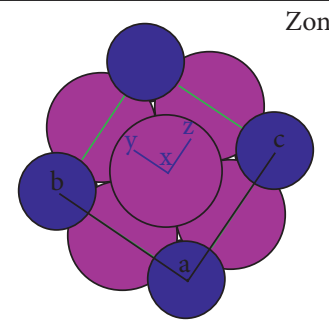

Crystalline structure of $\mathrm{Al}_{2} \mathrm{O}_{3}$

Zone axis: $(1,0,0)$

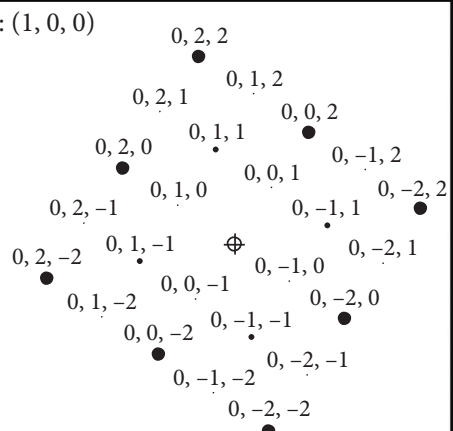

(f)

FIgURE 5: Microstructural characteristics of the Al- $\mathrm{CeO}_{2}$ sintered composite: (a) SEM micrograph, (b) TEM image, (c) close up of Ce-rich nanophase, (d) HRTEM micrograph showing the $\mathrm{CeO}_{2} / \mathrm{Al}$ interface, (e) corresponding simulated image, and (f) SAED and simulated patterns of the interface.

synthesized using a solid-state route complemented by mechanical milling. Used nanoceria has a particle size in the range of $10-50 \mathrm{~nm}$, its purity was confirmed by EDS, and the material presents a single-phase with a lattice constant of $5.411 \AA$ and Fm-3 m space group. The SEM and TEM studies revealed that the addition of $\mathrm{CeO}_{2}$ nanoparticles in the AA2024 alloy produced a dispersed needle- like $\mathrm{Ce}-\mathrm{Cu}$-rich phase, which changed their volume fraction, size, and morphology from irregular to a needlelike shape after sintering. A noticeable variation on the porosity as a direct function of the sintering time was also observed. The presence of this phase had a negative effect on the mechanical performance of the AA2024 alloy due to the chemical affinity between $\mathrm{Cu}$ and $\mathrm{Ce}$, which alter 


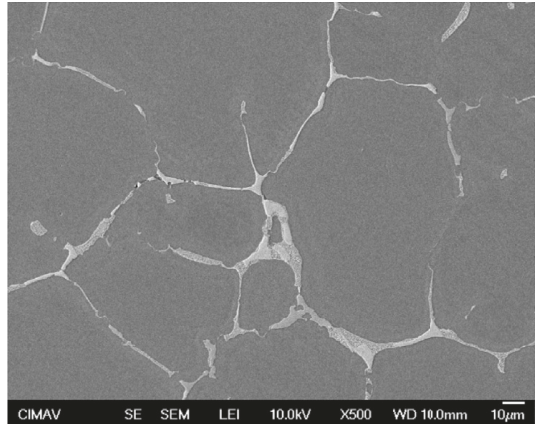

(a)

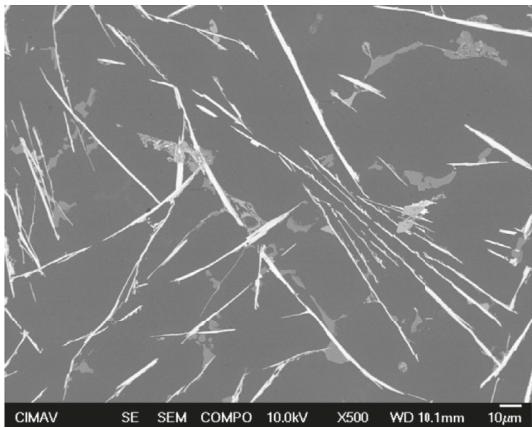

(b)

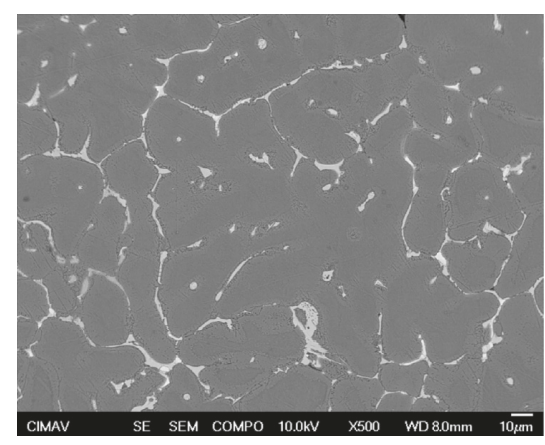

(c)

FIGURE 6: SEM micrographs showing the microstructure of samples in as-cast condition: (a) A2024, (b) A2024 + (A2024-CeO 2 ), and (c) $\mathrm{A} 2024+\left(\mathrm{Al}-\mathrm{CeO}_{2}\right)$.

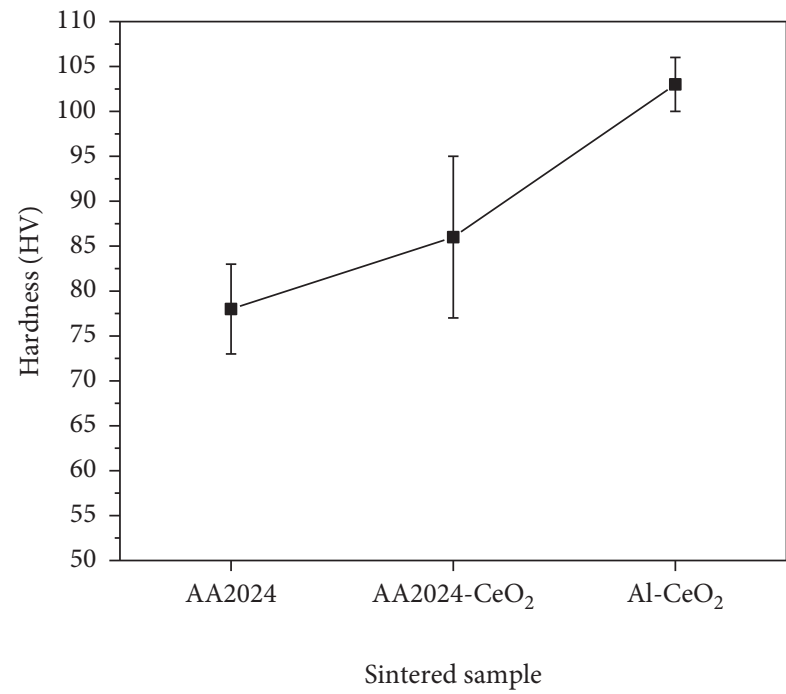

(a)

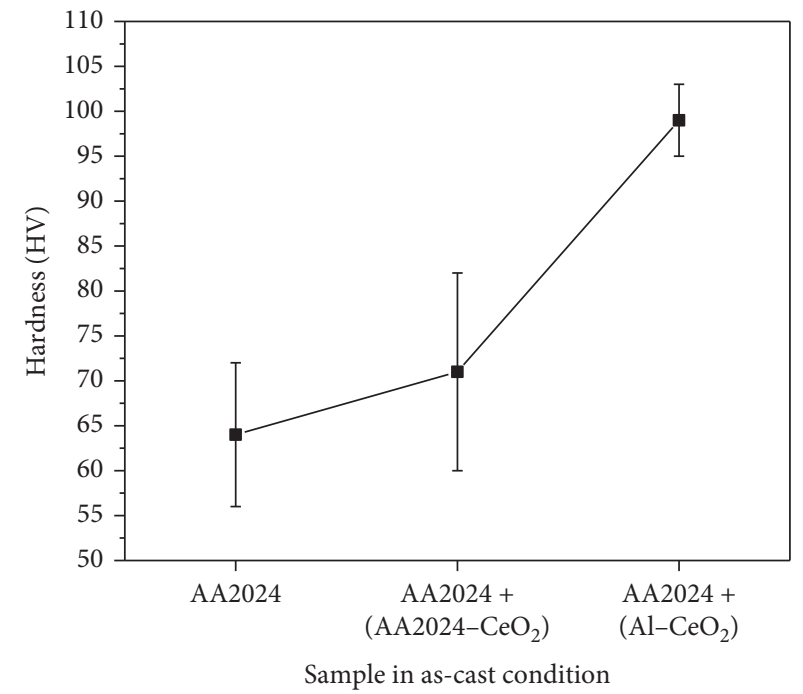

(b)

Figure 7: Mechanical behaviour of (a) sintered at $550^{\circ} \mathrm{C}$ for $3 \mathrm{~h}$ and (b) casted prepared samples.

the kinetics of precipitation of the $\mathrm{AlCuX}$ solutes. On the contrary, the dispersion of $\mathrm{CeO}_{2}$ in pure aluminum showed a significant improvement of hardness. During the melting, the $\mathrm{CeO}_{2}$ nanoparticles showed a similar chemical stability compared to low-temperature sintering processing. The remarkable microstructural variation of both metal matrixes is related with Ce-Cu affinity in the AA2024 alloy and the high chemical stability of the ceria nanoparticles in pure aluminum.

\section{Data Availability}

The data used to support the findings of this study are included within the article

\section{Conflicts of Interest}

The authors declare that there are no conflicts of interest regarding the publication of this paper.

\section{Acknowledgments}

The authors gratefully acknowledge K. Campos-Venegas, E. Guerrero-Lestarjette, and C.E. Ornelas-Gutiérrez for their technical assistance. This research was carried out with economical support from the National Council of Science and Technology (CONACYT) of Mexico (project no. 20450).

\section{References}

[1] I. Ozdemir, Y. Tsunekawa, C. Tekmen, and T. Grund, "Wear behavior of plasma-sprayed $\mathrm{Al}-\mathrm{Si} / \mathrm{TiB}_{2} / \mathrm{h}-\mathrm{BN}$ composite coatings," Journal of Thermal Spray Technology, vol. 19, no. 12, pp. 384-391, 2009.

[2] R. N. Rao, S. Das, D. P. Mondal, G. Dixit, and S. L. Tulasi Devi, "Dry sliding wear maps for AA7010 (Al-Zn-Mg-Cu) aluminium matrix composite," Tribology International, vol. 60, pp. 77-82, 2013. 
[3] H. Shi, E.-H. Han, F. Liu, and S. Kallip, "Protection of 2024-T3 aluminium alloy by corrosion resistant phytic acid conversion coating," Applied Surface Science, vol. 280, pp. 325-331, 2013.

[4] A. M. Al-Qutub, A. Khalil, N. Saheb, and A. S. Hakeem, "Wear and friction behavior of Al6061 alloy reinforced with carbon nanotubes," Wear, vol. 297, no. 1-2, pp. 752-761, 2013.

[5] H. T. Shivaramu, K. S. Umashankar, and D. A. Prashantha, "Wear sCharacteristics comparison of cast and powder metallurgy based Al and Al-Si alloy [LM6]," Materials Today: Proceedings, vol. 5, no. 2, pp. 8138-8146, 2018.

[6] L. N. Roger, Fundamentals of Aluminium Metallurgy: Chapter 4-Aluminium Investment Casting and Rapid Prototyping for Aerospace Applications, Elsevier, Amsterdam, Netherlands, 2018.

[7] M. R. Rosenberger, E. Forlerer, and C. E. Schvezov, "Wear behavior of AA1060 reinforced with alumina under different loads,"Wear, vol. 266, no. 1-2, pp. 356-359, 2009.

[8] X. Song, H. Yan, and X. Zhang, "Microstructure and mechanical properties of Al-7Si-0.7Mg alloy formed with an addition of $(\mathrm{Pr}+\mathrm{Ce})$," Journal of Rare Earths, vol. 35, no. 4, pp. 412-418, 2017.

[9] H. Hassannejad, M. Moghaddasi, E. Saebnoori, and A. R. Baboukani, "Microstructure, deposition mechanism and corrosion behavior of nanostructured cerium oxide conversion coating modified with chitosan on AA2024 aluminum alloy," Journal of Alloys and Compounds, vol. 725, pp. 968975, 2017.

[10] M. Saeedikhani, M. Javidi, and S. Vafakhah, "Anodising of 2024-T3 aluminium alloy in electrolyte of sulphuric- boricphosphoric mixed acid containing cerium salt as corrosion inhibitor," Transactions of Nonferrous Metals Society of China, vol. 27, no. 3, pp. 711-721, 2017.

[11] A. Uhart, J. B. Ledeuil, D. Gonbeau et al., "An Auger and XPS survey of cerium active corrosion protection for AA2024-T3 aluminum alloy," Applied Surface Science, vol. 390, pp. 751759, 2016.

[12] A. Pandey, A. K. Jain, S. Hussain, V. Sampath, and R. Dasgupta, "Effect of nano $\mathrm{CeO}_{2}$ addition on the microstructure and properties of a Cu-Al-Ni shape memory alloy," Metallurgical and Materials Transactions B, vol. 47, no. 4, pp. 2205-2210, 2016.

[13] L. Tian-Jiao, Y. Guang-chun, W. Lin-Li et al., "Influence of $\mathrm{CeO}_{2}$ on microstructure and tensile properties of 2024 aluminium alloy," Chinese Rare Earths, vol. 2, pp. 20-25, 2007.

[14] I. Sadeghi, M. A. Wells, and S. Esmaeili, "Effect of particle shape and size distribution on the dissolution behavior of $\mathrm{Al} 2$ $\mathrm{Cu}$ particles during homogenization in aluminum casting alloy Al-Si-Cu-Mg," Journal of Materials Processing Technology, vol. 251, pp. 232-240, 2018.

[15] R. Pérez-Bustamante, A. Reyna-Cruz, D. C. Acosta-Peña et al., "Effect of cerium/lanthanum addition on microstructure and mechanical properties of Al7075 alloy via mechanical alloying and sintering," Journal of Rare Earths, vol. 34, no. 4, pp. $420-427,2016$.

[16] L.-M. Wu, W.-H. Wang, Y.-F. Hsu, and S. Trong, "Effects of homogenization treatment on recrystallization behavior and dispersoid distribution in an Al-Zn-Mg-Sc-Zr alloy," Journal of Alloys and Compounds, vol. 456, no. 1-2, pp. 163-169, 2008.

[17] D. S. Khaerudini, K. Muljadi, P. Sardjono et al., "Effect of $\mathrm{CeO}_{2}$ addition on the properties of $\mathrm{FeAl}$ based alloy produced by mechanical alloying technique," AIP Conference Proceedings, vol. 7, p. 1555, 2013. 


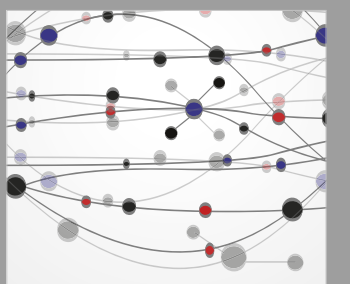

The Scientific World Journal
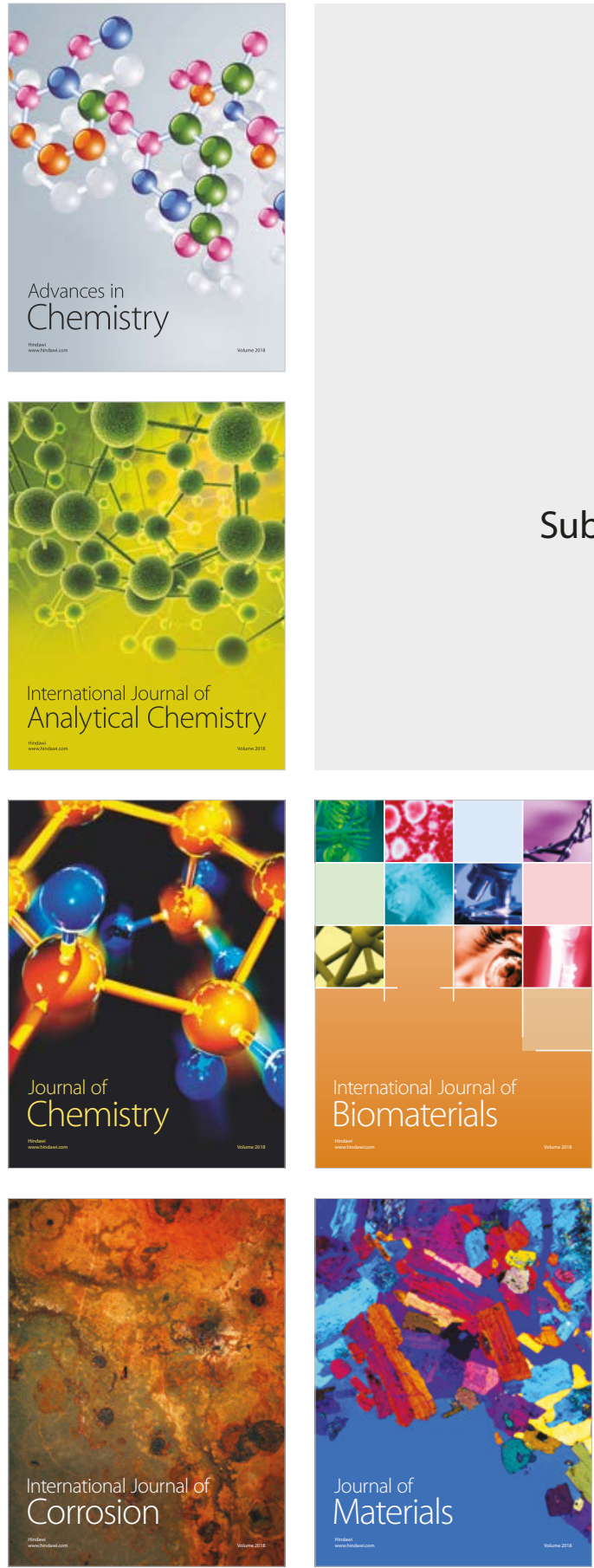

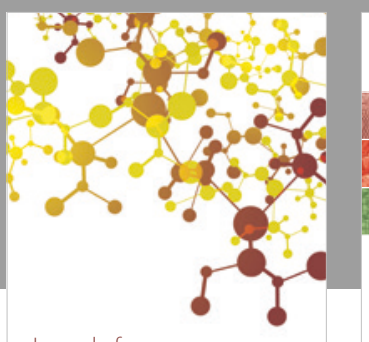

Journal of

Applied Chemistry
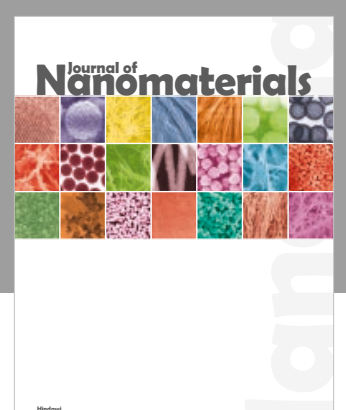

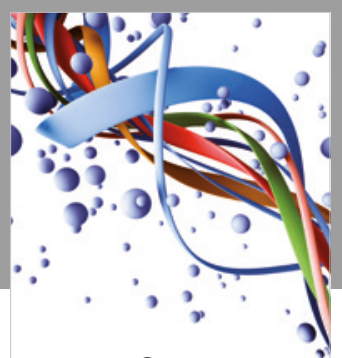

Scientifica

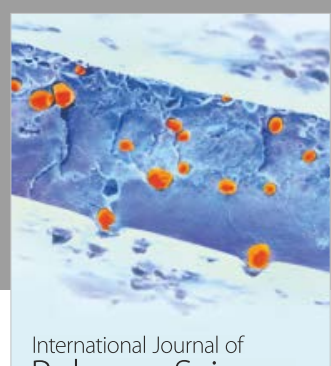

Polymer Science

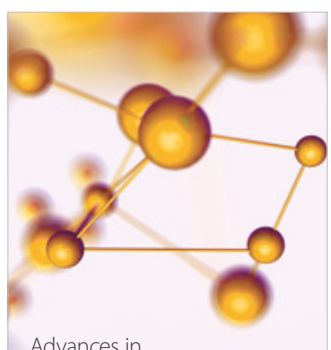

Physical Chemistry
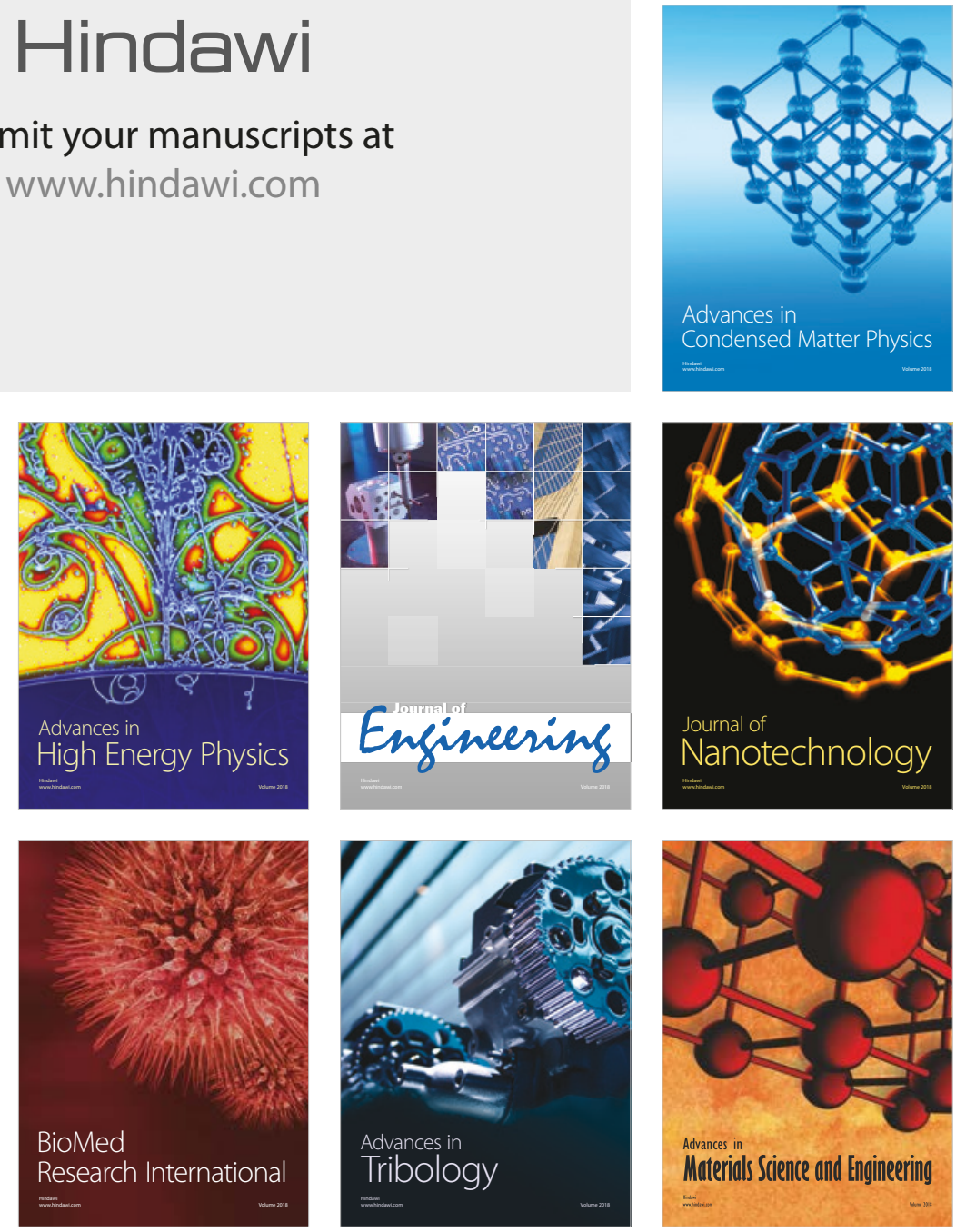